\title{
Clinical Practices and Therapeutic Management of Mineral and Bone Disorders in Chronic Kidney Disease 4, 5 and 5D: The OCEANOS Study
}

\section{in Iran}

\author{
Mohsen Nafar, ${ }^{1,2}$ Farin Rashid Farokhi, ${ }^{2,3}$ Abbas Ali Zeraati, ${ }^{4}$ Shahrzad Ossareh, ${ }^{5}$ Abdolah Atapour, ${ }^{6}$ \\ Eghlim Nemati, ${ }^{7}$ Fatemeh Poor Reza Gholi, ${ }^{8}$ Mohammad Mahdi Sagheb, ${ }^{9}$ Monir Sadat Hakemi, ${ }^{10}$ \\ Hassan Argani, ${ }^{11}$ Seied Ahmad Tara, ${ }^{12}$ Reza Afshar, ${ }^{13}$ Javad Mohamd Reza Ahmadi, ${ }^{14}$ Nadia Karimi, ${ }^{14}$ \\ Fereshteh Mamdouhi, ${ }^{15}$ Mitra Mahdavi-Mazdeh, ${ }^{16}$ and Tahereh Sabaghian ${ }^{2,17,{ }^{*}}$
}

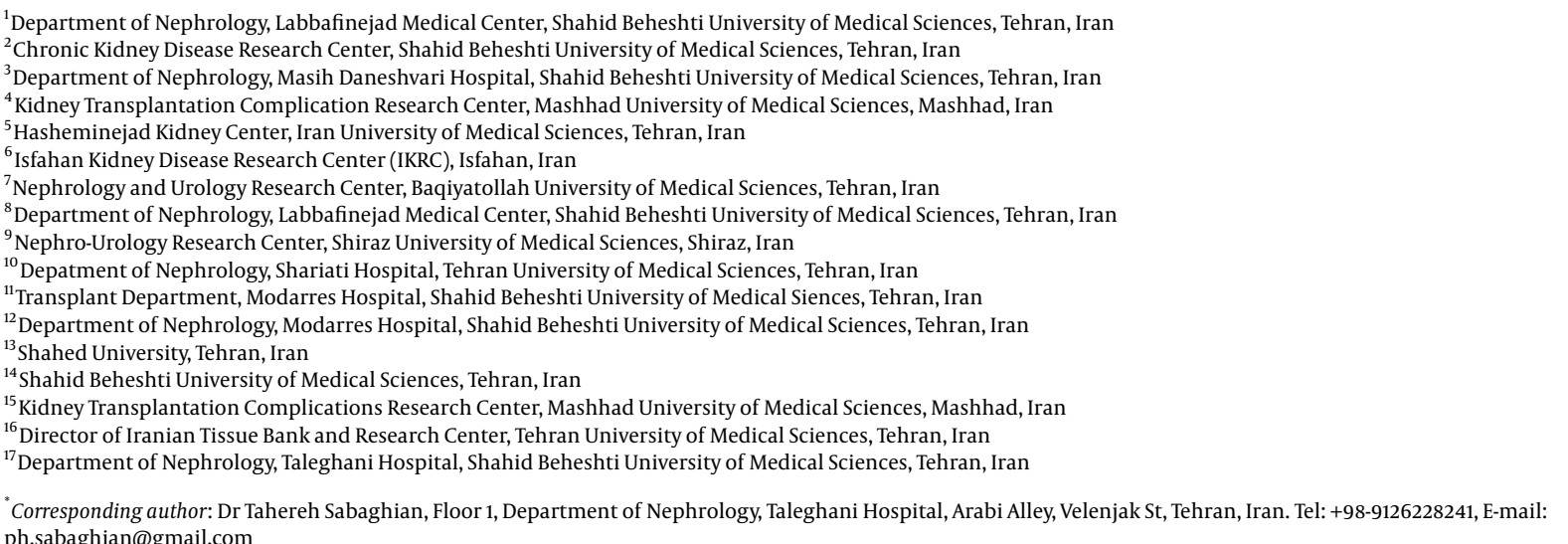
ph.sabaghian@gmail.com

Received 2017 September 12; Accepted 2017 October 12.

\begin{abstract}
Background: The aim of this study was to evaluate the management of mineral and bone disorders (MBD) in patients with chronic kidney disease (CKD) in Iran and the extent to which KDIGO goals were met.

Methods: This multi-centre observational study was conducted on patients with CKD stages 4, 5, and 5D. Data were collected from a total of 209 patients with no surgical or medical conditions that precluded their participation. This study assessed the frequency of measurements, serum levels of phosphorus (P), calcium (Ca), and parathyroid hormone (PTH), the achievement of the targets recommended by the $2009 \mathrm{KDIGO}$ guidelines, and the presence of vascular/valvular calcification.

Results: The KDIGO targets for P, Ca, and iPTH, were achieved in $47 \%, 51 \%$, and $18 \%$ of the patients with stage $4+5$ and in $63 \%$, $50 \%$, and $44 \%$ of the patients with stage $5 \mathrm{D}$, respectively. The serum PTH level of $18 \%$ of the patients with CKD stage $4+5$ was within the recommended range, while it was higher than the recommended level in other patients. Among patients with CKD stage 5D, the serum PTH level was within, below, and above the recommended range in $44 \%, 39 \%$, and $17 \%$ of the patients, respectively. The frequency of the measurement of the blood levels of Ca, P, and PTH were based on the 2009 KDIGO guidelines in $88 \%$ of patients. Forty-six percent of cases were screened for vascular/valvular calcification, $30 \%$ of whom had calcification at least in one site.

Conclusions: The current status is far from the targets recommended by the current guidelines in the management of CKD-MBD.
\end{abstract}

Keywords: Chronic Kidney Disease, Mineral and Bone Disorders, Calcium, Phosphorus, Parathyroid Hormone (PTH)

\section{Background}

Chronic kidney disease (CKD) is a complex disease with an annual incidence of 200 cases per million occurring in many countries (1). Nowadays, chronic kidney diseasemineral and bone disorder (CKD-MBD) is defined as a syndrome, which includes bone abnormalities, laboratory abnormalities, and vascular calcification, which are associated with cardiovascular diseases (CVD), bone deformity and fractures, and increased mortality (2). Cardiovascular diseases are the leading cause of mortality in CKD patients (3). Increased serum phosphorous level has been shown to be independently associated with an excessive risk of cardiovascular diseases in CKD patients $(4,5)$. Hyperphosphatemia also induces hyperparathyroidism, which can lead to bone loss, bone marrow fibrosis, and fractures (6). With the progression of chronic kidney disease, there is an increase in serum phosphate level, which can later become an important challenge for clinicians. Therefore, a key focus is correction of serum phosphorus through the re- 
striction of dietary phosphate and administration of phosphate binders.

To improve the quality of care in patients with CKD, various international guidelines, including the KDIGO bonemineral disease guidelines are published to be used in the management of CKD-MBD; the guidelines have suggested monitoring of phosphate (P), calcium (Ca), and serum PTH levels decrease cardiovascular diseases in patients with CKD stage 3 and higher (7-9). However, several studies have reported a gap between the content of international guidelines and actual practice (10-12). New studies have emphasized on the type of drug for management of CKDMBD to reduce cardiovascular disease. A prospective cohort study showed an increased rate of survival in dialysis patients treated with phosphate binders, as compared with patients not receiving phosphate binders (13). In addition, a systematic review showed that, in comparison with patients, who used calcium phosphate binders, the risk of all-cause mortality decreased in patients with chronic kidney disease, who received non-calcium phosphate binders (14).

This observational study aimed at assessing the adherence to and achievement of the KDIGO bone-mineral targets and studying the factors that hinder the achievement of the KDIGO targets.

\section{Methods}

This multi-center observational study was part of a larger study called OCEANOS(Multi-national observational study on clinical practices and therapeutic management of mineral and bone disorders in chronic kidney disease 4, 5 and 5D). This study, which was conducted on Iranian patients, began in June 2013 and continued until March 2014. To detect and diagnose CKD patients, the KDIGO 2009 guidelines were used (8).

\subsection{Physician and Patients Selections}

Adult patients (age $>18$ years) with CKD stages 4,5 , and $5 \mathrm{D}$, who were followed at 13 medical centers in Iran were enrolled in this study. Exclusion criteria were as follows: having an estimated glomerular filtration rate (eGFR) of $\geq$ $30 \mathrm{~mL} /$ minute $/ 1.73 \mathrm{~m}^{2}$, participation in an interventional trial, or presence of any medical or surgical condition, which might preclude patient' participation in the study (as judged by the researcher). A total of 210 CKD patients were enrolled, of whom 209 patients met the inclusion criteria. All of the physician who participated in this study, were nephrologists and, taking into account their geographic distribution, they were randomly selected for participation in the study.

\subsection{Ethical Issues}

Written informed consent was obtained from all of the patients. Moreover, ethical approval was obtained from the ethics committee of the chronic kidney disease research center of Shahid Beheshti University of Medical Sciences.

\subsection{Data Collection}

A checklist was used to assess physicians' knowledge of CKD-MBD guidelines, which included questions on physicians' age, gender, specialty, years of practice, main workplace, type of institution, number of dialyses performed per year in the studied center, and knowledge of and adherence to international guidelines.

Case report forms (CRF) were used to record data on patients' characteristics and medical history including age, blood pressure, body mass index(BMI), co-morbidities, history of smoking, cause and duration of CKD, history of parathyroidectomy, current use of medications, presence of vascular/valvular calcification, related methods of assessment, and CKD stage. Also, data was collected regarding time since the first dialysis, type of dialysis, and mean frequency of hemodialysis in CKD stage 5D.

Taking in consideration the CKD stage, the study evaluated different biochemical laboratory tests, such as serum Ca, P, PTH, 25 (OH) Vitamin D, albumin, creatinine, hemoglobin, LDL, cholesterol, presence of vascular and valvular calcifications, and methods of evaluation via CT scan, X-ray, and ultrasound. Serum Ca and P were measured using immunometric assays, and PTH was measured using an immunoradiometric assay.

The primary evaluation criterion was to assess the achievement of the KDIGO target ranges for serum $\mathrm{PTH}$, $\mathrm{Ca}$, and $\mathrm{P}$ alone and all together ( $\mathrm{Ca}, \mathrm{P}, \mathrm{PTH})$ and adherence to the KDIGO guideline was defined as meeting both criteria of the target range and frequency measurement. The secondary evaluation criteria were the followings: 1, assessment of current type and dose of medications for the management of CKD-MBD; 2, assessment of uncontrolled MBD, which is defined as patients not achieving at least one KDIGO-CKD-MBD target for Ca, P, and serum PTH levels (either in combination or individually); and 3, assessment of the methods used for screening valvular/vascular calcification and the type of calcium-based phosphate binders used for patients with one or more calcifications. Estimated glomerular filtration rate (eGFR) was calculated using the equation developed for the modification of diet in renal disease (MDRD-4) (15).

\subsection{Statistical Analysis}

The collected data was analyzed using the SPSS software, version 18 (SPSS Inc., Chicago, IL). Quantitative vari- 
ables were reported as range, median, mean, and standard deviation; categorical variables were presented as frequencies and percentages.

\section{Results}

\subsection{Physicians' Characteristics}

Sixteen nephrologists working at 13 medical centers participated in this study. The mean age of the physicians was $46 \pm 3$ (38 to 52) years and the median duration of their practice was 15 ( 8 to 25 ) years. All of the physicians were familiar with the international guidelines of KDIGO and kidney disease outcomes quality initiative(KDOQI). According to their own feedbacks, about $75 \%$ of the physicians were following the guidelines in their practices.

\subsection{Patients' Characteristics}

Table 1 shows the general characteristics of the patients. Eighty-nine patients (43\%) were females and 120 (57\%) were males. The mean age of the patients was 56 \pm 16 (18 to 95 ) years. There was no significant difference between the patients' age among different stages of CKD. Overall, $45 \%$ of the patients were aged older than 60 years.

The number of the patients with CKD stages 4,5, and 5D was 43,24 , and 142 , respectively. Of all, $68 \%$ of the patients were classified as stage 5D, $97 \%$ of whom (138 patients) were receiving hemodialysis. The mean frequency of hemodialysis was three times a week. Peritoneal dialysis was performed only in 4 patients (3\%). Diabetic nephropathy was the most common cause of CKD (Figure 1). Parathyroidectomy was performed on 15 patients (7\%). Dialysate Ca concentration was $2.5 \mathrm{mEq} / \mathrm{L}$ in all the dialysis patients.

\subsection{Primary Analysis}

The mean (SD) serum P, Ca, and PTH level in patients with stage $4+5$ were $4.8 \pm 1.1 \mathrm{mg} / \mathrm{dL}, 8.9 \pm 0.8 \mathrm{mg} / \mathrm{dL}$, and $158.6 \pm 151.4 \mathrm{pg} / \mathrm{dL}$, respectively. The mean (SD) serum P, Ca, and PTH level in patients with stage 5D were $5.3 \pm 1.4 \mathrm{mg} / \mathrm{dl}$, $8.9 \pm 1.0 \mathrm{mg} / \mathrm{dL}$, and $352.6 \pm 385.3 \mathrm{pg} / \mathrm{dL}$, respectively.

The target range of serum $P$ level recommended by the KDIGO guidelines for all of the patients with CKD stage 4,5 , and 5D was 2.5 - $4.5 \mathrm{mg} / \mathrm{dL}$ and $2.5-5.5 \mathrm{mg} / \mathrm{dL}$, respectively. Overall, in $47 \%$ of the patients with CKD stages $4+5$ (Table 2 ) and in $63.3 \%$ of the patients with CKD stage $5 \mathrm{D}$ (Table 3 ), the serum $P$ level was within the recommended KDIGO range. In $58 \%$ of the patients, serum P level was within the KDIGO recommended range, while it was lower or higher than the recommended range, in $0.6 \%$ and $41.4 \%$ of the patients, respectively.

It was found that nearly half of the patients (50\%) had a serum Ca level within the target range recommended by the KDIGO guidelines ( $8.5-9.5 \mathrm{mg} / \mathrm{dL}$ ) while in $28.6 \%$ it was lower than $8.5 \mathrm{mg} / \mathrm{dL}$ and in $21.4 \%$ was higher than 9.5 $\mathrm{mg} / \mathrm{dL}$ (Table 4).

The data about serum PTH level was available only for $60 \%$ of the patients. The KDIGO target range of serum PTH level recommended for CKD stages 4 and 5 ranged from equal or more than the lower limit of normal(LLN) to equal or less than the upper limit of normal (ULN); in CKD stage 5D, it was 2 to 9 times higher than the ULN. The normal range of serum PTH level was 15 to $65 \mathrm{pg} / \mathrm{mL}$. It was found that the serum PTH levels of $44 \%$ of the patients with CKD stage $5 \mathrm{D}$ and $18 \%$ of the patients with stages $4+5$ were within the KDIGO recommended range (Table 5, Figures 2 and 3). Among patients outside the guideline range for $\mathrm{PTH}$, a greater number of patients in stage $4+5$ were in the higher than target range, while more patients in stage 5D were in the lower than the target range. The percentage of the patients, who met all the KDIGO target ranges for $\mathrm{Ca}, \mathrm{P}$, and PTH was relatively low: stage $4+5,5 \%$; stage 5D, $11 \%$; all the patients, $9 \%$.

In $94 \%$ of patients, the frequency of $\mathrm{P}$ and Ca measurements (regardless of the disease stage) was consistent with the KDIGO recommended frequency (Figure 4). In $83 \%$ of the patients, all the three laboratory tests were performed. Figure 5 shows the frequency of the 3 measurements (Ca, P, and PTH) in the patients, who had undergone all the 3 tests; in addition, it presents the comparison between the measured values and the KDIGO guideline values. Among all of the patients in whom all of the 3 tests had been performed, the frequency of measurements was consistent with the rates recommended by KDIGO guidelines in $88 \%$.

Only $9 \%$ of the patients had performed all the 3 laboratory tests and met the KDIGO target ranges, thus 91\% did not meet the KDIGO adherence criteria. So although $88 \%$ of the frequency of measurements were consistent with the KDIGO guideline, the adherence to KDIGO was very low (9\%), with lower rate in CKD stage $4+5$ (5\%) than CKD stage 5D (10\%) (Figure 6).

\subsection{Secondary Analysis}

This study assessed current and ongoing medications and found that $67 \%$ of all patients used anti-hypertensive agents, $47 \%$ received lipid-lowering drugs, $28 \%$ were on insulin, and $6 \%$ received oral anti-diabetic agents. Overall, $87 \%$ of the patients were taking a phosphate binder. The type of phosphate binder used at each CKD stage was also evaluated (Table 6). Of all the patients, who used phosphate binders, 91.8\% received calcium-based phosphate binders, $8 \%$ used sevelamer, and only one patient received an oral calcimimetic agent ( $0.5 \%)$.

Overall, $67 \%$ of the patients received vitamin D supplements. Most of them were taking active vitamin $\mathrm{D}$ with a 
Table 1. General Patients' Characteristics by Chronic Kidney Disease Stage

\begin{tabular}{|c|c|c|c|}
\hline Parameter & Stage $4+5+5 D(N=209)$ & Stage $4+5(N=67)$ & Stage $5 \mathrm{D}(\mathrm{N}=142)$ \\
\hline Age, $y$ & $56 \pm 16$ & $57 \pm 15$ & $56 \pm 16$ \\
\hline Male & $120(57)$ & $39(58)$ & $81(57)$ \\
\hline BMI, $\mathrm{Kg} / \mathrm{m}^{2}$ & $24.8 \pm 4.6$ & $25.3 \pm 4.2$ & $24.5 \pm 4.8$ \\
\hline$<25$ & $115(55)$ & $33(49.3)$ & $82(57.7)$ \\
\hline$\geq 25$ & $94(45)$ & $34(50.7)$ & $60(42.3)$ \\
\hline Alkaline phosphatase, IU/L & $344 \pm 318$ & $277 \pm 118$ & $370 \pm 365$ \\
\hline Serum albumin, $g / L$ & $40 \pm 4.5$ & $40 \pm 4.2$ & $40 \pm 4.6$ \\
\hline Hemoglobin, g/dL & $11.4 \pm 1.7$ & $11.6 \pm 1.9$ & $11.4 \pm 1.6$ \\
\hline LDL-Cholesterol, $\mathbf{m m o l} / \mathrm{L}$ & $2.4 \pm 0.8$ & $2.6 \pm 0.8$ & $2.2 \pm 0.8$ \\
\hline Serum creatinine, $\mathrm{mg} / \mathrm{dL}$ & $5.2 \pm 1.4$ & $4.8 \pm 1.1$ & $5.3 \pm 1.4$ \\
\hline Creatinine clearance, $\mathrm{mL} / \mathrm{min}$ & $13 \pm 7.1$ & $19.6 \pm 7.4$ & $9.9 \pm 4.1$ \\
\hline Serum Bicarbonate- $\mathrm{HCO}_{3}, \mathrm{Meq} / \mathrm{L}$ & $20.6 \pm 3.6$ & $21.5 \pm 5.8$ & $20.2 \pm 2.6$ \\
\hline
\end{tabular}

Abbreviations: BMI, Body Mass Index; CKD, Chronic Kidney Disease; LDL, Low-Density Lipoprotein

${ }^{\mathrm{a}}$ Values are expressed as mean $\pm \mathrm{SD}$ (standard deviation) or No. (\%).

Table 2. Serum Phosphorous Level Based on KDIGO Guidelines in Chronic Kidney Disease Stage 4 and $5^{\text {a }}$

\begin{tabular}{|c|c|c|c|}
\hline Serum P level, KDIGO Target Range, mg/dL & Stage 4 & Stage 5 & Total (Stage $4+5$ ) \\
\hline$<2.5$ & $0(0)$ & $0(0)$ & $0(0)$ \\
\hline 2.5 to 4.5 & $29(69)$ & $2(8)$ & $31(47)$ \\
\hline$>4.5$ & $13(31)$ & $22(92)$ & $35(53)$ \\
\hline
\end{tabular}

Abbreviations: CKD, Chronic Kidney Disease; KDIGO Guidelines, Kidney Disease; Improving Global Outcomes Guidelines; P, Phosphorous.

${ }^{\mathrm{a}}$ Values are expressed as NO. (\%).

Table 3. Serum Phosphorous Level Based on KDIGO Guidelines in Chronic Kidney Disease Stage 5D

\begin{tabular}{ll}
\hline Serum P Level KDIGO Target Range (Stage $5 \mathrm{D}), \mathrm{mg} / \mathrm{dL} / \mathrm{N}=139$ & No. (\%) \\
\hline$<2.5$ (Less than KDIGO) & $1(0.7)$ \\
$\mathbf{2 . 5}$ to 5.5 (According to KDIGO) & $88(63.3)$ \\
$>\mathbf{5 . 5}$ (Greater than KDIGO) & $50(36)$ \\
\hline
\end{tabular}

Abbreviations: CKD, Chronic Kidney Disease; KDIGO Guidelines, Kidney Disease; Improving Global Outcomes Guidelines; P, Phosphorous.

Table 4. Serum Calcium Based on KDIGO Guidelines by Chronic Kidney Disease Stage (Eligible Patients' Population) ${ }^{\mathrm{a}}$

\begin{tabular}{|c|c|c|c|c|c|}
\hline Serum Ca KDIGO Range, mg/dL & Stage 4 & Stage 5 & Stage $(4+5)$ & Stage 5D & Total \\
\hline$<8.5$ & $13(30)$ & $5(21)$ & $18(27)$ & $41(30)$ & $59(28.6)$ \\
\hline 8.5 to 9.5 & $21(49)$ & $13(54)$ & $34(51)$ & $69(50)$ & $103(50)$ \\
\hline$>9.5$ & $9(21)$ & $6(25)$ & $15(22)$ & $29(20)$ & $44(21.4)$ \\
\hline
\end{tabular}

Abbreviations: Ca, Calcium; CKD, Chronic Kidney Disease; KDIGO Guidelines; Kidney Disease: Improving Global Outcomes Guidelines.

${ }^{\mathrm{a}}$ Values are expressed as No. (\%).

dosage of 0.75 to $7 \mathrm{mcg} /$ week (Table 6).

\subsection{Vascular/Valvular Calcification Screening}

Overall, 96 patients (46\%) had undergone at least one X-ray or ultrasound or computed tomography (CT) scan 


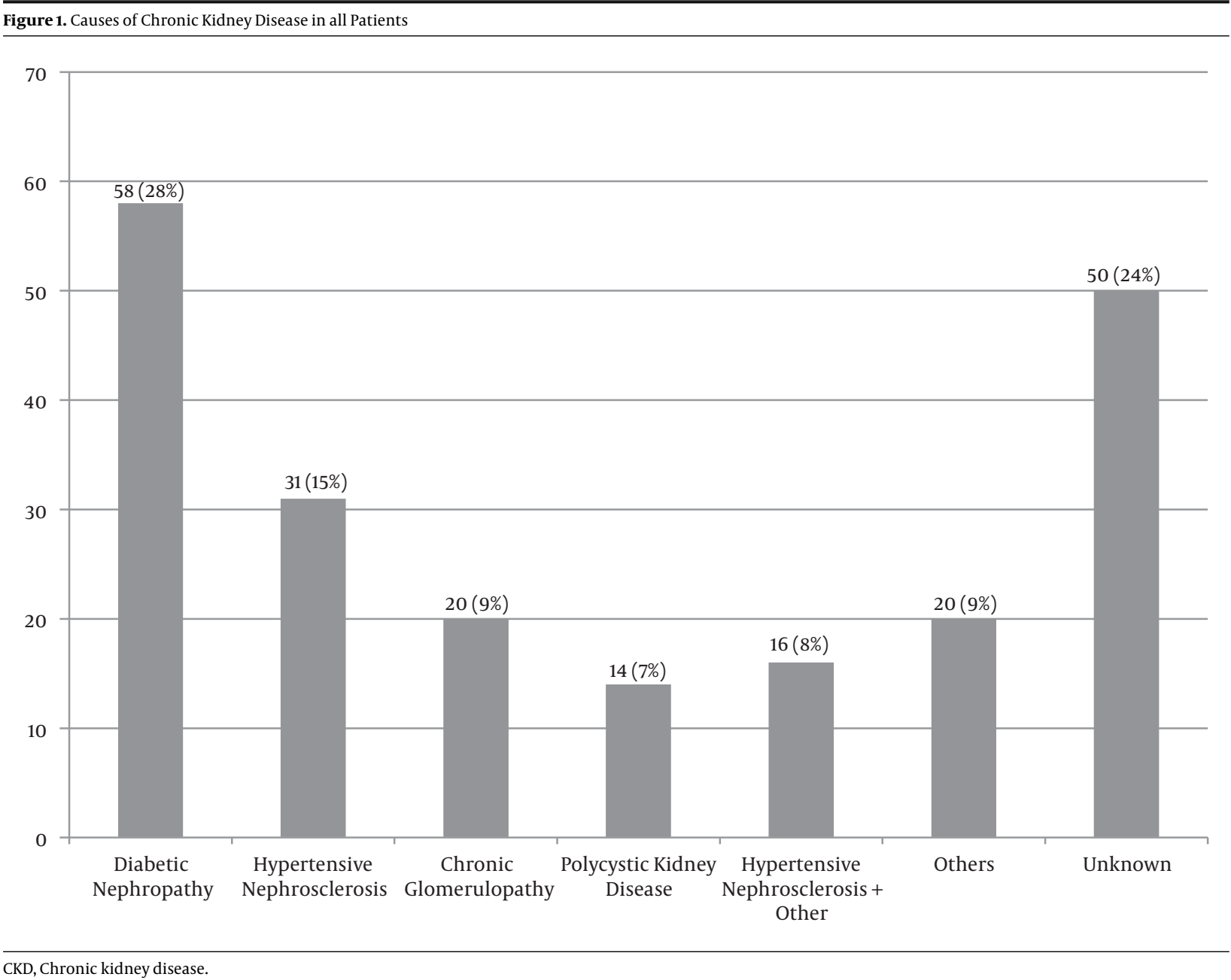

Table 5. Parathyroid Hormone Based on KDIGO Guidelines by Chronic Kidney Disease Stage ${ }^{\mathrm{a}}$

\begin{tabular}{|c|c|c|c|c|}
\hline Within KDIGO Target Range & Stage 4 & Stage 5 & Stage $4+5$ & Stage 5D \\
\hline Yes & $4(15)$ & $3(23)$ & $7(18)$ & $55(44)$ \\
\hline No & $22(84)$ & $10(77)$ & $32(82)$ & $69(56)$ \\
\hline
\end{tabular}

Abbreviations: CKD, Chronic Kidney Disease; KDIGO Guidelines, Kidney Disease; Improving Global Outcomes Guidelines; PTH, Parathyroid Hormone.

${ }^{\mathrm{a}}$ Values are expressed as No. (\%).

to screen for vascular/valvular calcification. Of these, $30 \%$ (29/96) had at least one calcification. Ultrasound was the most frequently used screening test used for detecting calcification. Table 7 presents details on vascular/valvular calcification screening.

3.6. Physician's Adherence to Kidney Disease and Current Chronic Kidney Disease Treatment

Overall, $9.2 \%$ of the patients achieved all the KDIGO target ranges and $8.6 \%$ adhered to the KDIGO guidelines, when all the 3 laboratory tests were done (Table 8). The number of years of physicians practice did not affect their adherence to the KDIGO guidelines.

Table 9 presents data on current and ongoing CKD treatments in patients, who were followed up by a nephrologist. The number of patients receiving phosphate binder was higher than those receiving other types of drug such as vitamin D or calcimimetic drugs. 
Table 6. Type of Ongoing Phosphate Binder and Vitamin D Receptor Agonist by Chronic Kidney Disease Stage

\begin{tabular}{|c|c|c|c|c|c|}
\hline Parameter & Stage $4(N=43)$ & Stage $5(N=24)$ & Stage $5 \mathrm{D}(\mathrm{N}=142)$ & Stage $4+5(N=67)$ & Stage $4+5+5 D(N=209)$ \\
\hline \multicolumn{6}{|l|}{ Phosphate binder } \\
\hline Yes & $31(72)$ & $16(67)$ & $135(95)$ & $47(70)$ & $182(87)$ \\
\hline No & $12(28)$ & $8(33)$ & $7(5)$ & $20(30)$ & $27(13)$ \\
\hline \multicolumn{6}{|l|}{ Type of phosphate binder ${ }^{b}$} \\
\hline Aluminum-based binder & $1(3)$ & $0(0)$ & $3(2)$ & $1(2)$ & $4(2)$ \\
\hline Lanthanum-based binder & $0(0)$ & $0(0)$ & $0(0)$ & $0(0)$ & $0(0)$ \\
\hline Calcium-based binder & $30(97)$ & $16(100)$ & $121(90)$ & $46(98)$ & $167(92)$ \\
\hline Calcium acetate & $0(0)$ & $1(6)$ & $7(5)$ & $1(2)$ & $8(4)$ \\
\hline Calcium carbonate & $30(97)$ & $15(94)$ & $115(85)$ & $45(96)$ & $160(88)$ \\
\hline Non-calcium, non-metal based & $1(3)$ & $0(0)$ & $32(24)$ & $1(2)$ & $33(8)$ \\
\hline \multicolumn{6}{|l|}{ Oral calcimimetic agent } \\
\hline Yes & $0(0)$ & $0(0)$ & $1(0.7)$ & $0(0)$ & $1(0.5)$ \\
\hline No & $43(100)$ & $24(100)$ & $141(99.3)$ & $67(100)$ & $208(99.5)$ \\
\hline Vitamin D & $28(65.1)$ & $12(50)$ & $100(70.4)$ & $40(59.7)$ & $140(67)$ \\
\hline Native vitamin D & $4(14.3)$ & $0(0)$ & $21(21)$ & $4(10)$ & $25(17.9)$ \\
\hline $25(\mathrm{OH})$ vitamin D & $3(10.7)$ & $0(0)$ & $3(3)$ & $3(7.5)$ & $6(4.3)$ \\
\hline Active vitamin $\mathrm{D}(1,25(\mathrm{OH})$ vitamin $\mathrm{D})$ & $23(82.1)$ & $12(100)$ & $84(84)$ & $35(87.5)$ & $119(85)$ \\
\hline
\end{tabular}

Abbreviation: CKD: Chronic Kidney Disease.

${ }^{\mathrm{a}}$ Values are expressed as No. (\%).

${ }^{\mathrm{b}}$ Some patients used more than one types of phosphate binder.

Table 7. Screening Test Performed and Observation of Vascular/Valvular Calcification ${ }^{\mathrm{a}}$

\begin{tabular}{|c|c|c|c|c|c|}
\hline Parameter & Stage $4, N=43$ & Stage $5, N=24$ & Stage $5 \mathrm{D}, \mathrm{N}=142$ & Stage $4+5, N=67$ & Total, $\mathbf{N}=\mathbf{2 0 9}$ \\
\hline Patients with at least one test performed & $17(40)$ & $6(25)$ & $73(51)$ & $23(34)$ & $96(46)$ \\
\hline \multicolumn{6}{|c|}{ Among patients with at least one test performed } \\
\hline at least 1 calcification observed & $3(18)$ & $1(17)$ & $25(34)$ & $4(17)$ & $29(30)$ \\
\hline \multicolumn{6}{|c|}{ Among patients with at least one calcification observed } \\
\hline 1st screening test & $2(67)$ & $1(100)$ & $15(60)$ & $3(75)$ & $18(62)$ \\
\hline 2nd screening test & $1(33)$ & $0(0)$ & $10(40)$ & $1(25)$ & $11(38)$ \\
\hline 3rd screening test & $0(0)$ & $0(0)$ & $0(0)$ & $0(0)$ & $0(0)$ \\
\hline X-ray & $\mathrm{N}=14(32.6)$ & $\mathrm{N}=2(8.3)$ & $\mathrm{N}=42(29.6)$ & $\mathrm{N}=16(23.9)$ & $\mathrm{N}=58(27.7)$ \\
\hline at least 1 calcification observed & $1(7.1)$ & $0(0)$ & $9(21.4)$ & $1(6.3)$ & $10(17.2)$ \\
\hline Ultrasound & $\mathrm{N}=16(37.2)$ & $\mathrm{N}=6(25)$ & $N=61(43)$ & $\mathrm{N}=22(3.3)$ & $\mathrm{N}=83(39.8)$ \\
\hline at least 1 calcification observed & $3(18.8)$ & $1(16.7)$ & $23(37.7)$ & $4(18.1)$ & $27(32)$ \\
\hline CT scan & $\mathrm{N}=0(0)$ & $\mathrm{N}=0(0)$ & $\mathrm{N}=7(4.9)$ & $\mathrm{N}=0(0)$ & $\mathrm{N}=7(3.3)$ \\
\hline at least 1 calcification observed & $0(0)$ & $0(0)$ & $6(85.8)$ & $0(0)$ & $6(85.8)$ \\
\hline
\end{tabular}

${ }^{\mathrm{a}}$ Values are expressed as No. (\%).

\subsection{Diabetes Status Sub-Group Analysis}

Overall, $34 \%$ of the patients had diabetes, $93 \%$ of whom had diabetes type 2. Of all the patients with CKD stages 4,
5, and 5D, 26\%, $13.7 \%$, and $60.3 \%$, respectively, were patients with diabetes. The percentage of patients whose serum 
Table 8. Physicians' Characteristic According to Patient's Adherence to KDIGO Guidelines ${ }^{\mathrm{a}}$

\begin{tabular}{|c|c|c|c|c|c|c|}
\hline \multirow{3}{*}{$\begin{array}{l}\text { Physician's } \\
\text { Characteristics }\end{array}$} & \multicolumn{6}{|c|}{ Patient Data } \\
\hline & \multicolumn{2}{|c|}{ All KDIGO Targets Ranges Met } & \multicolumn{2}{|c|}{ Frequency of Measurements Follow KDIGO Guidelines } & \multicolumn{2}{|c|}{ Adherence to KDIGO Guideline } \\
\hline & $\operatorname{Yes}(\mathrm{N}=15)$ & No $(N=147)$ & $\operatorname{Yes}(N=143)$ & No $(N=19)$ & $\operatorname{Yes}(\mathbf{N}=14)$ & No $(N=148)$ \\
\hline \multicolumn{7}{|l|}{ Specialty } \\
\hline Nephrologist & $15(100)$ & $147(100)$ & $143(100)$ & $19(100)$ & $14(100)$ & $148(100)$ \\
\hline \multicolumn{7}{|l|}{ Main workplace } \\
\hline Hemodialysis center & $6(40.0)$ & $17(11.6)$ & $17(11.9)$ & $6(31.6)$ & $5(35.7)$ & $18(12.2)$ \\
\hline Nephrology department & $7(46.7)$ & $100(68.0)$ & $101(70.6)$ & 6(31.6) & $7(50.0)$ & $100(67.6)$ \\
\hline \multicolumn{7}{|l|}{ Institution type } \\
\hline Public & $4(26.7)$ & $91(61.9)$ & $84(58.7)$ & $11(57.9)$ & $3(21.4)$ & $92(62.2)$ \\
\hline Private & $0(0.0)$ & $0(0.0)$ & $o(0.0)$ & $0(0.0)$ & $0(0.0)$ & $0(0.0)$ \\
\hline Mixed (public and private) & $11(73.3)$ & $56(38.1)$ & $59(41.3)$ & $8(42.1)$ & $11(78.6)$ & $56(37.8)$ \\
\hline \multicolumn{7}{|l|}{ Number of CKD patients followed-up } \\
\hline$<1000$ & $6(40.0)$ & $85(57.8)$ & $82(57.3)$ & $9(47.4)$ & $5(35.7)$ & $86(58.1)$ \\
\hline $1000-5000$ & $9(60.0)$ & $62(42.2)$ & $61(42.7)$ & $10(52.6)$ & $9(64.3)$ & $62(41.9)$ \\
\hline \multicolumn{7}{|l|}{ Declared to follow } \\
\hline KDIGO guidelines & $11(73.3)$ & $107(72.8)$ & $105(73.4)$ & $13(68.4)$ & $10(71.4)$ & $108(73.0)$ \\
\hline $\mathrm{K} / \mathrm{DOQI}$ guidelines & $11(73.3)$ & $120(81.6)$ & $118(82.5)$ & $13(68.4)$ & $10(71.4)$ & $121(81.8)$ \\
\hline Know any other guidelines & $11(73.3)$ & $83(56.5)$ & $92(64.3)$ & $2(10.5)$ & $11(78.6)$ & $83(56.1)$ \\
\hline
\end{tabular}

Abbreviations: KDIGO guidelines, Kidney Disease; Improving Global Outcomes Guidelines; K/DOQI Guidelines, Kidney Disease Outcomes Quality Initiative Guidelines. Abbreviations: KDIGo guidel
$\mathrm{a}_{\text {Any values are number }(\%) \text {. }}$.

Table 9. Physicians' Characteristic According to Current or Ongoing Chronic Kidney Disease Treatment ${ }^{\mathrm{a}}$

\begin{tabular}{|c|c|c|c|}
\hline \multirow[t]{2}{*}{ Physician's Characteristics } & \multicolumn{3}{|c|}{ Patient Treatment Data } \\
\hline & Phosphate Binder $(\mathrm{N}=182)$ & Oral Calcimimetic $(\mathrm{N}=\mathbf{1})$ & Vitamin $D(N=140)$ \\
\hline \multicolumn{4}{|l|}{ Specialty } \\
\hline \multicolumn{4}{|l|}{ Main workplace } \\
\hline Hemodialysis center & $24(13.2)$ & $1(100)$ & $15(10.8)$ \\
\hline Nephrology department & $122(67)$ & $0(0)$ & $95(67.8)$ \\
\hline Other & $36(19.8)$ & $0(0)$ & $30(21.4)$ \\
\hline \multicolumn{4}{|l|}{ Institution type } \\
\hline Public & $99(54)$ & $0(0)$ & $68(49)$ \\
\hline Private & $0(0)$ & $0(0)$ & $0(0)$ \\
\hline Mixed “public” and “private” & $83(46)$ & $1(100)$ & $72(51)$ \\
\hline \multicolumn{4}{|l|}{ Number of CKD patients followed-up } \\
\hline $1000-5000$ & $82(45)$ & $1(100)$ & $69(49)$ \\
\hline \multicolumn{4}{|l|}{ Declared to follow } \\
\hline KDIGO guidelines & $135(74)$ & $1(100)$ & $97(69)$ \\
\hline K/DOQI guidelines & $146(80)$ & $1(100)$ & $105(75)$ \\
\hline Know any other guidelines & $101(56)$ & $1(100)$ & $85(61)$ \\
\hline
\end{tabular}

Abbreviations: KDIGO guidelines, Kidney Disease; Improving Global Outcomes Guidelines; K/DOQI Guidelines, Kidney Disease Outcomes Quality Initiative Guidelines.

${ }^{a}$ Any values are number $(\%)$

Ca level was within the KDIGO target range was lower in patients with diabetes than in non-diabetic patients (44\% versus 53\%), yet the percentage of patients whose serum PTH level was within the KDIGO target range was higher in patients with diabetes than in non-diabetic patients $(50 \%$ versus 32.1\%). There was no significant difference between the 2 groups in terms of adherence to the KDIGO guideline for serum $P$ level. In addition, there was no significant difference between the 2 groups in terms of the percentage of patients with diabetes that were taking a phos- 
Figure 2. Parathyroid Hormone Based on KDIGO guidelines in Chronic Kidney Disease Stage $4+5$

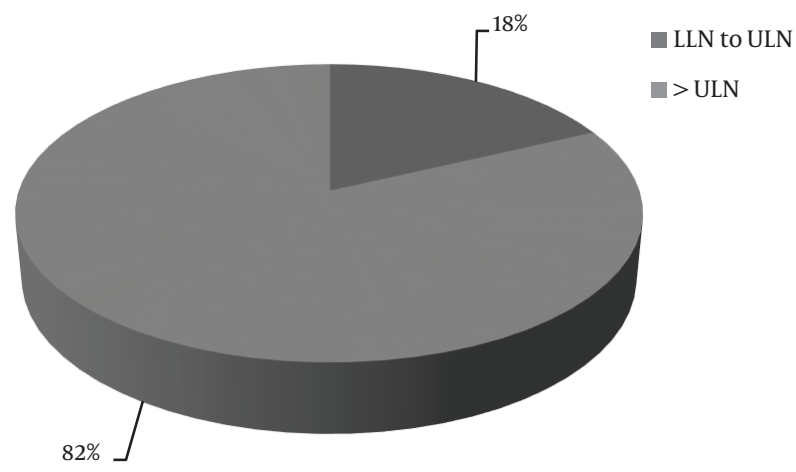

LLN, Lower limit of normal of PTH; ULN, Upper limit of normal of PTH.

phate binder and the type of phosphate binder; however, non-calcium phosphate binders were used slightly more in patients without diabetes than in patients with diabetes. There was no statistically significant difference between the 2 groups of diabetic and non-diabetic patients in terms of adherence to the KDIGO guideline, meeting all KDIGO target ranges, and the frequency of measurement as recommended by KDIGO guidelines. As compared with nondiabetic patients, a higher number of patients with diabetes had at least one calcification (34.5\% versus $28.4 \%$ ).

\section{Discussion}

Hyperphosphatemia is recognized as a risk factor for CVD and is associated with $20 \%$ to $40 \%$ rise in the risk of allcause mortality and deaths from coronary artery diseases in patients on dialysis (16-18). In addition, Ca and P disorders and dose of elemental Ca existing in calcium phosphate binder are known risk factors for vascular calcification in patients with CKD. Moreover, vascular calcification is a strong prognostic marker for all-cause mortality and cardiovascular mortality in patients on dialysis (19). Hyperphosphatemia and hypercalcemia are also considered risk factors for calciphylaxis (20). Thus, it is of great importance to maintain the target levels of Ca and P via modifying diet and using efficient dialysis and appropriate phosphate binders. Various types of calcium-based and noncalcium based phosphate binders are available. Apparently, there is a correlation between the dose of calciumbased phosphate binder and calcium load on aortic calcification $(21,22)$.

In this multicenter observational study, 209 patients with CKD stage 4 to $5 \mathrm{D}$ from different parts of Iran were investigated. In nearly $100 \%$ of the patients, serum Ca and
P levels were measured, however PTH level was measured only in $77 \%$ of the patients. Overall, in $93 \%$ of cases, the frequency of monitoring serum Ca and P levels was consistent with KDIGO recommendations. In addition, in $88 \%$ of cases, the frequency of measuring all the 3 markers of $\mathrm{Ca}$, $\mathrm{P}$, and serum PTH levels was consistent with the KDIGO recommended frequency. Compared with a tertiary care center in India (with Ca and P monitoring frequency of 8\%), the frequency of monitoring Ca, P, and PTH serum levels in Iran seems to be much more favorable (23).

Regarding the target levels, almost half of the patients were in the target range of serum Ca level and more than half of the patients were in the target range of serum P level recommended by the KDIGO. In a multi-center study in China, patients with CKD stage 5D showed better $\mathrm{P}$ and $\mathrm{Ca}$ serum level, as compared with patients on hemodialysis ( $\mathrm{P}$ : $63 \%$ versus $38 \%$; Ca: $50 \%$ versus $39 \%$ ) (24). This is consistent with the results of dialysis outcomes and practice patterns study (DOPPS), 2011, which was conducted on hemodialysis patients in USA and Canada that reported rates of $52 \%$ and $55 \%$ for serum P target ranges and $53.7 \%$ and $63.1 \%$ for serum Ca target ranges, respectively (25).

Of all the patients with stage $4+5$ CKD, $82 \%$ had hyperparathyroidism; hypoparathyroidism was not observed in any of the patients. Nevertheless, in the majority of patients with stage 5D disease, failure to achieve PTH targets could be mainly attributed to the high percentage of patients with low PTH and possibly adynamic bone disease, considering that $39 \%$ of patients received hemodialysis having PTH levels less than $150 \mathrm{pg} / \mathrm{mL}$ (as compared with hyperparathyroidism, which was observed in 17\%). This result is almost consistent with the results of 2 studies in Korea and India, conducted on patients receiving hemodialysis; according to the results of the two studies, PTH $>300$ was observed in $26.5 \%$ and $28 \%$ and $\mathrm{PTH}<150$ was observed in $42.7 \%$ and $46 \%$ of the patients, respectively $(26,27)$. On the other hand, patients in the present study had a better serum mineral profile, as compared with the results of another study on hemodialysis patients in Iran conducted during year 2005 (Ca: $53 \%$ versus 50\%, P: $52 \%$ versus $63 \%$ respectively); in addition, the prevalence of $\mathrm{PTH}<150 \mathrm{pg} / \mathrm{mL}$ was lower than that observed in a previous study (39\% versus $48.1 \%$ ) (28). In the DOPPS 2011 study, which was conducted on patients with CKD stage 5D in Canada and USA, the serum PTH level was between 150 and $600 \mathrm{pg} / \mathrm{mL}$ in $67.5 \%$ and $47.1 \%$, respectively, lower than $150 \mathrm{pg} / \mathrm{mL}$ in $19.8 \%$ and $25.9 \%$, respectively, and higher than $600 \mathrm{pg} / \mathrm{mL}$ in $12.7 \%$ and $26.9 \%$, respectively (25). This result shows the higher prevalence of adynamic bone disease in Asian patients, as compared with Canadian and American patients. Overall, $67 \%$ of all patients and $70 \%$ of patients under hemodialysis were taking active vitamin $\mathrm{D}$, which could explain the 


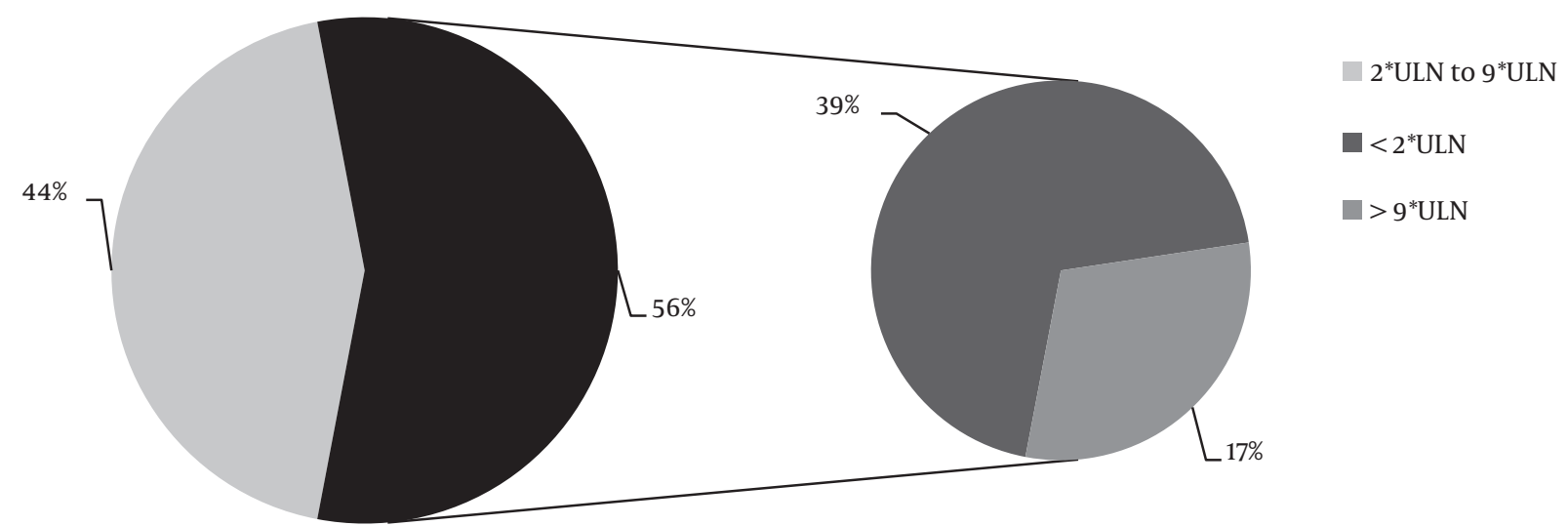

Purple color: outside of KDIGO target range for PTH. CKD, Chronic kidney disease; KDIGO guidelines, Kidney Disease; Improving Global Outcomes guidelines; PTH, Parathyroid hormone; ULN, Upper limit of normal of PTH.

Figure 4. Frequency of Measurements of serum Ca and P levels Based on KDIGO

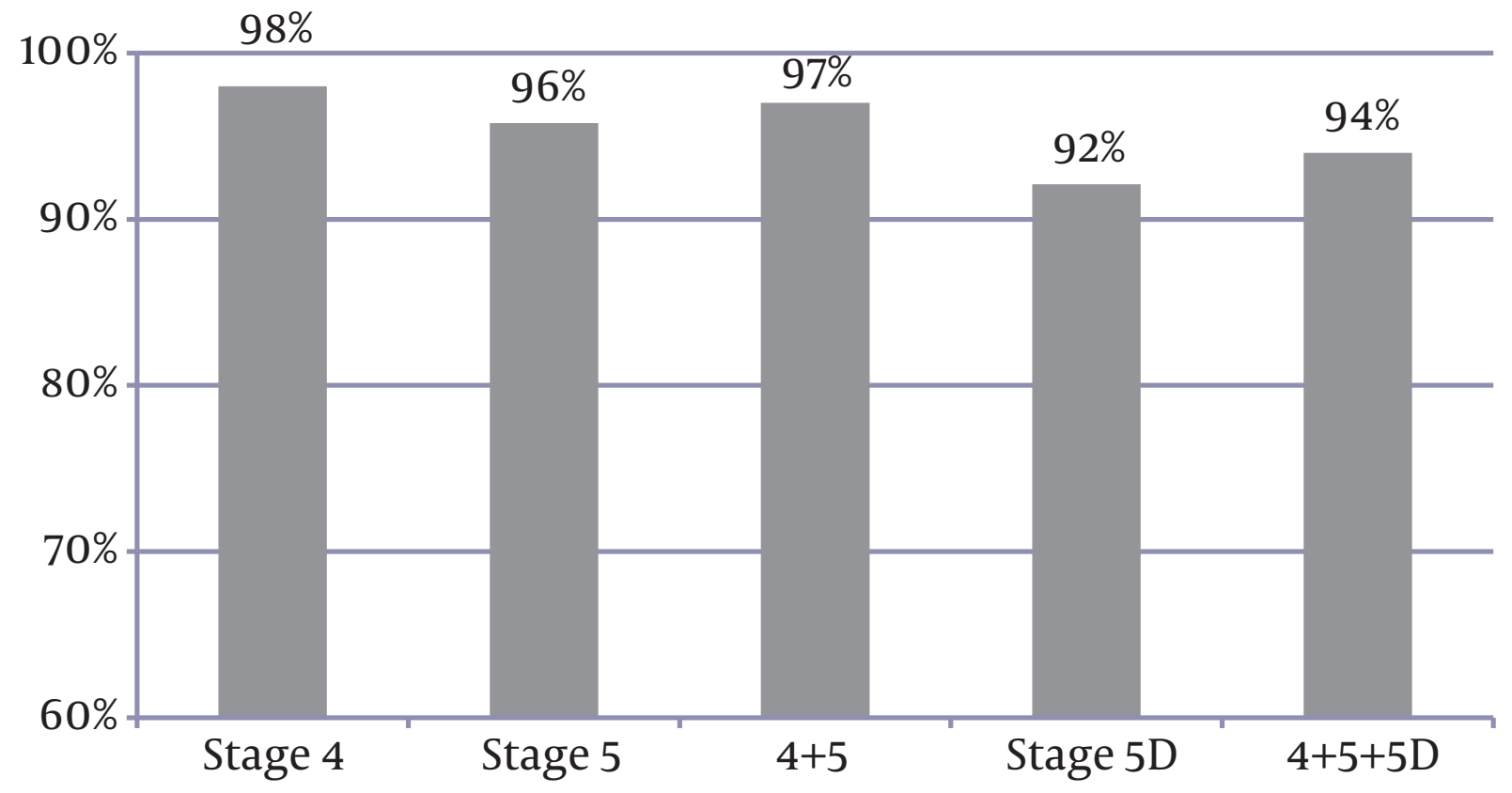

Ca, Calcium; P, Phosphorus; KDIGO guidelines, Kidney Disease; Improving Global Outcomes guidelines.

presence of hypercalcemia and adynamic bone disease.

In a large number of patients, the frequency of monitoring serum levels of these markers was consistent with the KDIGO recommended frequency. Of all the patients, 9.3\% met the targets recommended for all the 3 markers of $\mathrm{Ca}, \mathrm{P}$, and PTH. However, only a very small percentage of the patients (9\%) had total adherence to all KDIGO guidelines in terms of both the optimum frequency of monitoring of
PTH, Ca and P, and achievement of the serum levels targets. Despite the higher percentage of monitoring serum levels of Ca, P, and PTH in stage $4+5$ patients, they were less successful than stage $5 \mathrm{D}$ patients, meeting the targets recommended by KDIGO except for Ca (P: 47\% versus 63\%, Ca: 51 $\%$ versus $50 \%$, and PTH: $18 \%$ versus $44 \%$ ). Given that the patients at the dialysis centers were visited at regular intervals by nephrologists, the observed difference is justifiable. 
Figure 5. Frequency of Three Measurements (Ca, P, and PTH) Respecting KDIGO Guideline in Patients Were Done for all Three Lab Tests

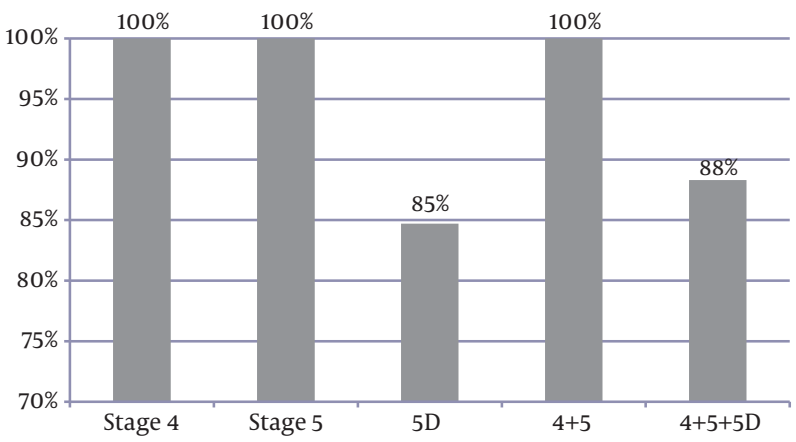

Ca, Calcium; P, Phosphorus; PTH, Parathyroid hormone; KDIGO guidelines, Kidney Disease; Improving Global Outcomes guidelines.

The majority of patients with stage 5D (95\%) and 70\% of patients with stage $4+5$ were taking phosphate binders. Of all, $94 \%$ used calcium carbonate, which was higher than the rates observed in US (73\%) and Canada (43.1\%) reported by DOPPS 2010 (25). In addition, there was no significant difference between the patients with different stages of the disease in terms of the type of phosphate binders, which they used. Non-calcium phosphate binders were used only in a small group of patients (8\%), which could explain the observed rate of hypercalcemia $(21 \%)$ in the studied patients. In a recent meta-analysis conducted by Jamal et al., a 22\%-decrease in mortality was observed after using noncalcium phosphate binders (sevelamer and lanthanum) (14). In addition, according to the results of a study by Elder et al. the use of sevelamer, as compared with calcium carbonate, was associated with less mortality in the patients with stage 3-5D CKD (29). As the current results showed, the studied patients were at a high risk of calcification and a moderate risk of hypercalcemia (Tables 4,7 ). In addition, because of the likely effect of calcium-based phosphate binders on vascular calcification and hypercalcemia and since the target levels of Ca and P were not achieved in this study, it seems necessary to pay special attention to the type and dose of phosphate binders and diet of patients.

Considering the frequency of monitoring, the observed value does not seem appropriate. These findings are not unique to the current study, as in many previous studies it has been difficult to reach the targets of KDIGO in mineral metabolism $(10,12,30,31)$. The key to success in managing $\mathrm{Ca}$ and $\mathrm{P}$ disorders in patients with CKD is to follow the international guidelines and maintain $\mathrm{Ca}, \mathrm{P}$, and serum PTH levels in the target range. The high percentage of nonadherence to KDIGO guidelines, which was observed in this study, may potentially be attributed to the high costs of ac- cess to non-calcium phosphate binders at the time of the study and possibly low adherence to diet.

As the guidelines have an important effect on the disease outcomes, it is necessary to study the factors hindering the accomplishment of the targets and eliminate the major obstacles hindering the achievements of the targets.

One of the limitations of the current study was the failure to investigate other factors affecting the management of CKD-MBD, including a phosphorus-rich diet and adequacy of dialysis. In addition, because of the observational nature of the study, it was not possible to find a causaleffect relationship for interpreting the values of the variables. In addition, it should be mentioned that this study was done on 2013 and the choice of phosphate binders has possibly changed since then, after Sevelamer has been covered by insurance companies in our country.

\subsection{Conclusion}

The findings of this study showed that CKD-MBD management in Iran is not currently optimal as meeting the targets recommended by the KDIGO guidelines has not been achieved. Given the importance of vascular calcification and the impact of mineral disorders in its development, it is of great importance to find the barriers to achieving these goals. Therefore, it is necessary to pay special attention to the patients' diet, restrict the use of phosphate, ensure dialysis adequacy, provide insurance for the patients, and ensure the availability of medicines and new treatments to reach the targets and reduce the complications.

\section{Footnotes}

Conflict of Interests: The authors declare no conflicts of interest.

Informed Consent: Informed consent was obtained from all participants included in the study.

Funding/Support: We received lecture fees from Sanofi and this work was supported by Sanofi.

\section{References}

1. Levey AS, Coresh J. Chronic kidney disease. Lancet. 2012;379(9811):16580. doi:10.1016/S0140-6736(11)60178-5. [PubMed: 21840587].

2. Ketteler M, Elder GJ, Evenepoel P, Ix JH, Jamal SA, Lafage-Proust MH, et al. Revisiting KDIGO clinical practice guideline on chronic kidney disease-mineral and bone disorder: a commentary from a Kidney Disease: Improving Global Outcomes controversies conference. Kidney Int. 2015;87(3):502-28. doi: 10.1038/ki.2014.425. [PubMed: 25651364].

3. Block GA, Hulbert-Shearon TE, Levin NW, Port FK. Association of serum phosphorus and calcium $\mathrm{x}$ phosphate product with mortality risk in chronic hemodialysis patients: a national study. Am J Kidney Dis. 1998;31(4):607-17. doi: 10.1053/ajkd.1998.v31.pm9531176. [PubMed 9531176]. 


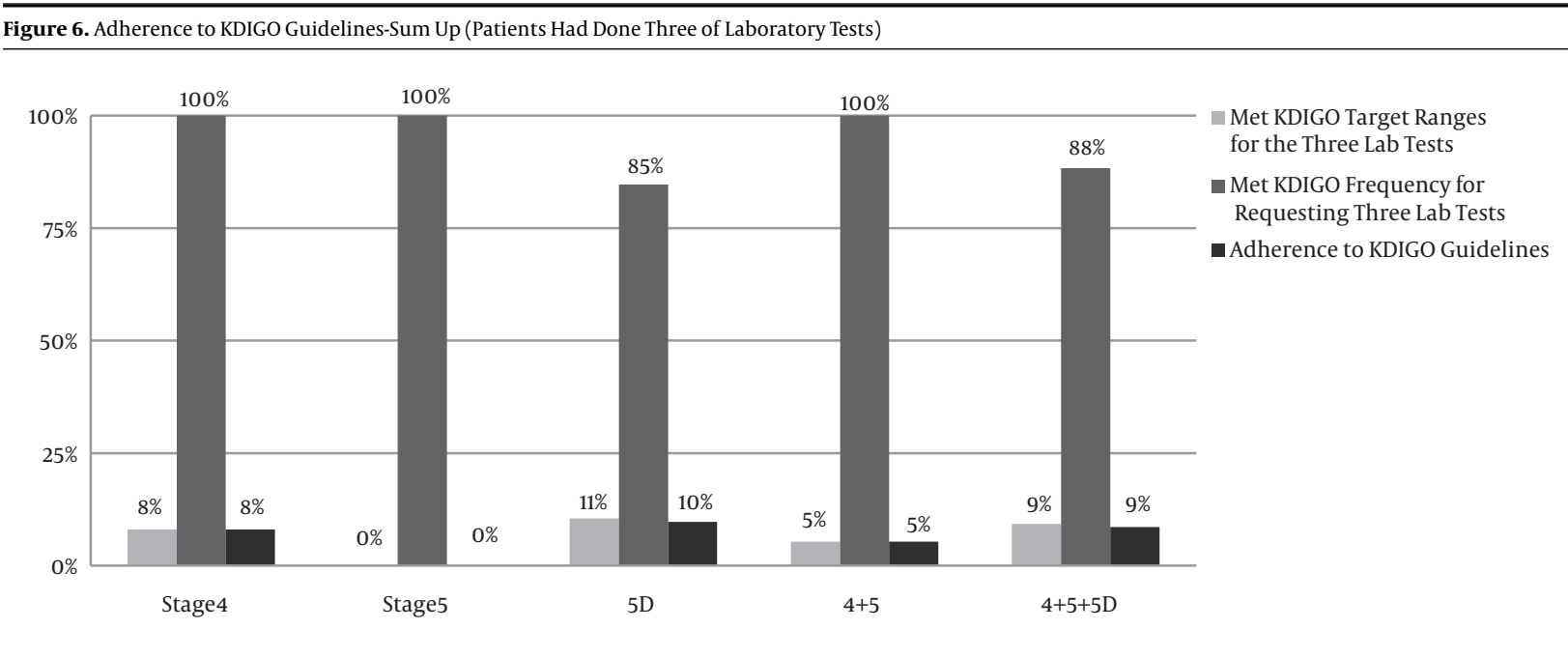

KDIGO guidelines, Kidney Disease: Improving Global Outcomes guidelines.

4. Atsumi K, Kushida K, Yamazaki K, Shimizu S, Ohmura A, Inoue T. Risk factors for vertebral fractures in renal osteodystrophy. Am J Kidney Dis. 1999;33(2):287-93. doi: 10.1016/S0272-6386(99)70302-1. [PubMed: 10023640].

5. Slatopolsky E, Brown A, Dusso A. Role of phosphorus in the pathogenesis of secondary hyperparathyroidism. Am J Kidney Dis. 2001;37(1 Suppl 2):S54-7. doi: 10.1053/ajkd.2001.20740. [PubMed: 11158862].

6. Stein MS, Packham DK, Ebeling PR, Wark JD, Becker GJ. Prevalence and risk factors for osteopenia in dialysis patients. Am J Kidney Dis. 1996;28(4):515-22. doi: 10.1016/S0272-6386(96)90461-8. [PubMed: 8840940].

7. Andrassy KM. Comments on 'KDIGO 2012 Clinical Practice Guideline for the Evaluation and Management of Chronic Kidney Disease'. Kidney Int. 2013;84(3):622-3. doi: 10.1038/ki.2013.243. [PubMed: 23989362].

8. Kidney Disease: Improving Global Outcomes CG. KDIGO clinical practice guideline for the diagnosis, evaluation, prevention, and treatment of Chronic Kidney Disease-Mineral and Bone Disorder (CKDMBD). Kidney Int Suppl. 2009;(113):S1-130. doi: 10.1038/ki.2009.188. [PubMed: 19644521].

9. National Kidney F. K/DOQI clinical practice guidelines for bone metabolism and disease in chronic kidney disease. Am J Kidney Dis. 2003;42(4 Suppl 3):S1-201. doi: 10.1016/S0272-6386(03)00905-3. [PubMed: 14520607].

10. Deger SM, Mutluay R, Derici U, Mandiralioglu F, Arinsoy T, Sindel S. Can calcium, phosphate, calcium phosphate product and intact parathyroid hormone levels be appropriately controlled in dialysis patients?. Med Princ Pract. 2011;20(1):85-9. doi: 10.1159/000319768. [PubMed: 21160221].

11. Kim GH. Gaps between Global Guidelines and Local Practices in CKD-MBD. Electrolyte Blood Press. 2014;12(2):35-40. doi: 10.5049/EBP.2014.12.2.35. [PubMed: 25606042].

12. Young EW, Akiba T, Albert JM, McCarthy JT, Kerr PG, Mendelssohn DC, et al. Magnitude and impact of abnormal mineral metabolism in hemodialysis patients in the Dialysis Outcomes and Practice Patterns Study (DOPPS). Am J Kidney Dis. 2004;44(5 Suppl 2):34-8. doi: 10.1016/S0272-6386(04)01103-5. [PubMed: 15486872].

13. Isakova T, Gutierrez OM, Chang Y, Shah A, Tamez H, Smith K, et al. Phosphorus binders and survival on hemodialysis. $J$ Am Soc Nephrol. 2009;20(2):388-96. doi: 10.1681/ASN.2008060609. [PubMed: 19092121].

14. Jamal SA, Vandermeer B, Raggi P, Mendelssohn DC, Chatterley T,
Dorgan M, et al. Effect of calcium-based versus non-calcium-based phosphate binders on mortality in patients with chronic kidney disease: an updated systematic review and meta-analysis. Lancet. 2013;382(9900):1268-77. doi: 10.1016/S0140-6736(13)60897-1. [PubMed: 23870817].

15. Levey AS, Bosch JP, Lewis JB, Greene T, Rogers N, Roth D. A more accurate method to estimate glomerular filtration rate from serum creatinine: a new prediction equation. Modification of Diet in Renal Disease Study Group. Ann Intern Med. 1999;130(6):461-70. doi: 10.7326/0003-4819-130-6-199903160-00002. [PubMed: 10075613].

16. Block GA, Klassen PS, Lazarus JM, Ofsthun N, Lowrie EG, Chertow GM. Mineral metabolism, mortality, and morbidity in maintenance hemodialysis. J Am Soc Nephrol. 2004;15(8):2208-18. doi: 10.1097/01.ASN.0000133041.27682.A2. [PubMed: 15284307].

17. Ganesh SK, Stack AG, Levin NW, Hulbert-Shearon T, Port FK. Association of elevated serum $\mathrm{PO}(4), \mathrm{Ca} \times \mathrm{PO}(4)$ product, and parathyroid hormone with cardiac mortality risk in chronic hemodialysis patients. J Am Soc Nephrol. 2001;12(10):2131-8. [PubMed: 11562412].

18. Rodriguez-Benot A, Martin-Malo A, Alvarez-Lara MA, Rodriguez M, Aljama P. Mild hyperphosphatemia and mortality in hemodialysis patients. Am J Kidney Dis. 2005;46(1):68-77. doi: 10.1053/j.ajkd.2005.04.006. [PubMed: 15983959].

19. London GM, Guerin AP, Marchais SJ, Metivier F, Pannier B, Adda H. Arterial media calcification in end-stage renal disease: impact on all-cause and cardiovascular mortality. Nephrol Dial Transplant. 2003;18(9):1731-40. doi: 10.1093/ndt/gfg414. [PubMed: 12937218].

20. Yang H, Curinga G, Giachelli CM. Elevated extracellular calcium levels induce smooth muscle cell matrix mineralization in vitro. Kidney Int. 2004;66(6):2293-9. doi: 10.1111/j.1523-1755.2004.66015.x. [PubMed: 15569318].

21. Goldsmith D, Covic A. Oral phosphate binders in CKD - is calcium the (only) answer?. Clin Nephrol. 2014;81(6):389-95. doi: 10.5414/CN108209. [PubMed: 25017668].

22. London GM, Marchais SJ, Guerin AP, Boutouyrie P, Metivier F, de Vernejoul MC. Association of bone activity, calcium load, aortic stiffness, and calcifications in ESRD. J Am Soc Nephrol. 2008;19(9):1827-35. doi: 10.1681/ASN.2007050622. [PubMed: 18480316].

23. Pavan M, Ranganath R, Chaudhari AP, Upadhayaya KL, Mehta HJ. Practice pattern of chronic kidney disease-mineral and bone disorder (CKD-MBD) in hemodialysis patients in a tertiary care centre in India. Dial Traspl. 2012;33(4):110-4. doi:10.1016/j.dialis.2011.12.001. 
24. Kong X, Zhang L, Zhang L, Chen N, Gu Y, Yu X, et al. Mineral and bone disorder in Chinese dialysis patients: a multicenter study. BMC Nephrol. 2012;13:116. doi: 10.1186/1471-2369-13-116. [PubMed: 22994525].

25. Robinson B, Fuller D, Zinsser D. The Dialysis Outcomes and Practice Patterns Study (DOPPS) Practice Monitor: rationale and methods for an initiative to monitor the new US bundled dialysis payment system. Am J Kidney Dis. 2011.

26. Jeloka T, Mali M, Jhamnani A, Konde S, Jadhav V. Are we overconcerned about secondary hyperparathyroidism and underestimating the more common secondary hypoparathyroidism in our dialysis patients?.J Assoc Physicians India. 2012;60:102-5. [PubMed: 22715556]

27. Kim GH, Choi BS, Cha DR, Chee DH, Hwang E, Kim HW, et al. Serum calcium and phosphorus levels in patients undergoing maintenance hemodialysis: A multicentre study in Korea. Kidney Res Clin Pract. 2014;33(1):52-7. doi: 10.1016/j.krcp.2013.12.003. [PubMed: 26877950].

28. Mahdavi-Mazdeh M, Zamyadi M, Norouzi S, Heidary Rouchi A. Man- agement of calcium and phosphorus metabolism in hemodialysis patients in Tehran Province, Iran. Iran J Kidney Dis. 2007;1(1):25-8. [PubMed: 19357440].

29. Patel L, Bernard LM, Elder GJ. Sevelamer Versus Calcium-Based Binders for Treatment of Hyperphosphatemia in CKD: A MetaAnalysis of Randomized Controlled Trials. Clin J Am Soc Nephrol 2016;11(2):232-44. doi: 10.2215/CJN.06800615. [PubMed: 26668024].

30. Rivera F, Sanchez de la Nieta MD, Echarri R, Anaya S, Carreno A, Voz mediano MC, et al. [CA-P control in haemodialysis and K/DOQI guidelines]. Nefrologia. 2006;26(3):351-7. [PubMed: 16892824].

31. Wei M, Taskapan H, Esbaei K, Jassal SV, Bargman JM, Oreopoulos DG. K/DOQI guideline requirements for calcium, phosphate, calcium phosphate product, and parathyroid hormone control in dialysis patients: can we achieve them?. Int Urol Nephrol. 2006;38(3-4):739-43. doi: 10.1007/s11255-005-0083-x. [PubMed: 17160632]. 